\title{
Impact of Front Line Demonstration on Scientific Temperament of Soybean Growers under the K.V.K. of Dhar District (M.P.)
}

\author{
${ }^{1}$ Mr. Kailash Chandra Jeengar, ${ }^{2}$ Dr. Sandhya Choudhary, ${ }^{3}$ Dr. V. K. Swarnakar \\ ${ }^{I}$ M.Sc. Extension Education Final Year Student 2012 \\ ${ }^{2}$ Associate Professor Extension Education, College of Agriculture, Indore \\ ${ }^{3}$ Professor \& Head Extension Education, College of Agriculture, Indore
}

\begin{abstract}
The main objective of the FLD is to demonstrate newly released crop production and protection technology and its management practices on the farmer's field by the scientists themselves before taking it into main extension system of State Department of Agriculture under different agro-climatic regions and in real farming system. Presently the FLDs are mainly conducted through KVKs in all over the country. This is the mandatory function of KVK to remove lack of knowledge and constraints in the adoption of improved soybean production technology. Keeping all these views in mind, the present investigation entitled "Impact of Front Line Demonstrations on Scientific Temperament of Soybean Growers under the K.V.K. of Dhar District (M.P.) with 104 respondents of Dhar District in M.P. The findings of the study imply that there is an impact of Front Line Demonstration on scientific temperament of the farmers. Hence, the demonstrations may increase the scientific temperament of the farmers.
\end{abstract}

\section{Introduction}

Soybean is known as the "GOLDEN BEAN" of the $20^{\text {th }}$ Century. Though, Soybean is a legume crop, yet it is widely used as oilseed. Due to very poor cookability on account of inherent presence of trypsin inhibitor, it cannot be utilized as a pulse. It is now the second largest oilseed in India after groundnut. It grows in varied agro-climatic conditions. It has emerged as one of the important commercial crop in many countries. Due to its worldwide popularity, the international trade of Soybean is spread globally. Several countries such as Japan, China, Indonesia, Philippines, and European countries are importing Soybean to supplement their domestic requirements for human consumption and cattle feed. The benefit of the technology would be harnessed better in case the matching extension efforts are also made. Demonstration is considered as most efficient tool for dissemination of information. Launching of the scheme of FLD during the year 1900-91 provided the required incentive and as a result the soybean varieties proved their potential under real firm situation demonstrated quantum jump to yield. The Krishi Vigyan Kendra is taken FLD as a one of the mandatory work. In this line Jatav and Patel (2010) reported that the majority of the respondents (beneficiaries of FLD program and non beneficiaries) possessed medium level of the scientific temperament. Again Vaghashia et al. (2005) studied the adoption of technology of FLD through technology index and recommended package of practices being followed by farmers. The result of Singh et al. (2005) reported that the FLD was effective in changing the attitude, skill and knowledge of improved / recommended practices of high yielding variety of rice including adoption. The frontline demonstration is different than the normal demonstrations conducted by the extension functionaries. FLDs are conducted under the close supervision of the scientists.

The KVK of Dhar district (M.P.) was mandatory entrusted with the responsibility of conducting FLD in Dhar district of M.P. The main emphasis was to maximize production per unit area by using high yielding varieties of soybean in conjunction with the package and practices. Keeping this in view for present study the following objective is set forth.

\section{Objective}

To determine the scientific temperament of the beneficiaries and non beneficiaries of FLD Program.

\section{Material \& Methods}

The study was conducted in 4 FLD villages of Dhar district of M.P. where FLDs were conducted by the KVK of Dhar district M.P. During 2007-08 to 2010-11, 52 soybean growers were benefited by this programme. All the beneficiary farmers, and same number of non-beneficiary farmers, were selected randomly from same villages of Dhar district (M.P.). Thus, 52 respondents were selected from KVK as the beneficiaries and 52 respondents as non beneficiaries from same villages to constitute the sample of the study.

Scientific temperament has been defined in this study as farmers' mental disposition related to items pertaining to four areas of human behaviour vis-à-vis scientific knowledge, scientific attitude, scientific habit and utilization of scientific method of soybean cultivation. For measuring extent of knowledge of the 
respondents, a list of practices of soybean cultivation was made. Questions were put to the respondents for which the answers were either 'yes' or 'no', and score was 1 for 'yes', and zero (0) for 'no'.

\section{Result \& Discussion}

Scientific temperament of FLD beneficiary and non beneficiary:

The scientific temperament of the beneficiaries of FLD programme and non-beneficiaries was measured with help of scientific temperament scale. Scientific temperament scale comprises of four components viz. scientific knowledge, scientific attitude, scientific habit and scientific method.

The percentage distribution of the respondents according to their scientific temperament is shown in Table

4.11. The perusal of data in the table reveals that majority (60.58\%) of the respondents possessed medium level of scientific temperament, while about (19.23\%) of the respondents possessed high and 20.19 per cent possessed low level of scientific temperament. similar finding was reported by $\mathrm{De}(2004)$ in case of potato.

In case of beneficiaries farmers, half $(57.69 \%)$ of the respondents had medium level of scientific temperament, while 36.54 per cent had high and only 5.77 per cent had low level of scientific temperament.

4.11: Distribution of the respondents according to their scientific temperament.

\begin{tabular}{|c|c|c|c|}
\hline Scientific temperament & Beneficiaries & Non-beneficiaries & Total \\
\hline Low $(<60.04)$ & $3(5.77)$ & $18(34.62)$ & $21(20.19)$ \\
\hline Medium(60.04-78.36) & $30(57.69)$ & $33(63.46)$ & $63(60.58)$ \\
\hline High(>78.36) & $19(36.54)$ & $1(1.92)$ & $20(19.23)$ \\
\hline Total & $\mathbf{5 2}$ & $\mathbf{5 2}$ & $\mathbf{1 0 4}$ \\
\hline Mean & $\mathbf{7 4 . 0 4}$ & $\mathbf{6 2 . 7 5}$ & $\mathbf{7 2 . 5}$ \\
\hline SD & $\mathbf{1 4 . 1 4}$ & $\mathbf{7 . 7 8}$ & $\mathbf{9 . 0 6}$ \\
\hline$' t$ ' $9.74 * *$ & & \\
\hline
\end{tabular}

(Figures in parenthesis indicate percentage

\section{Significant at .01 level of probability}

In case of non-beneficiary farmers, 63.46 per cent had medium level of scientific temperament, while, 34.62 per cent had low and only 1.92 per cent had high level of scientific temperament.

The table also presents the data regarding mean scientific temperament of the farmers. The data indicated that mean scientific temperament of total respondents was 72.5. The data also indicated that mean value of scientific temperament of beneficiary farmers of FLD was higher (74.04) than the mean score (62.75) of scientific temperament of non-beneficiaries.

The' $t$ ' test was used for testing the significant difference of mean score of scientific temperament of two groups (beneficiaries of FLD programme and non-beneficiaries) in relation to their scientific temperament.

The hypothesis under this test was that the beneficiaries of FLD programme and non-beneficiaries differ in their degree of scientific temperament. Therefore, the null hypothesis was rejected and the original hypothesis that there is a highly significant difference between scores mean of both the group was, accepted. Thus, it can be stated that there is an impact of FLD program on scientific temperament of the soybean growers. Similar result was reported by Jatav, H.R. and M.M. Patel (2010), Singh et al. (2005) and Patel.

Majority of the respondents (beneficiaries of FLD program and non-beneficiaries) possessed medium level of scientific temperament. The mean value of scientific temperament of beneficiary farmers of FLD was higher than the mean score of scientific temperament of non-beneficiaries. The ' $t$ ' test indicated that there is a significant difference between scores mean of both the group. Thus, it can be stated that, there is an impact of FLD program on scientific temperament of the soybean growers.

\section{Reference}

[1] Jatav, H.R. and M.M.Patel (2010). Impact of Front Line Demonstration on Scientific Temperament of soybean growers in Indore and Dewas districts of Madhya Pradesh. M.Sc. (Ag.) thesis submitted to J.N.K.V.V., Jabalpur

[2] Singh, Narahari, Angad Prasad and Daya Ram (2005) Frotline demonstration on rice in Manipur. Agri. Extn. Review.1 (2): 6-7

[3] Vaghasia, P.M., R.L. Savaii and G.R. Celaya (2005). Front Line Demonstration on groundnut, Rachis hypogeal Evaluation of L. in Saurashtra region of Gujarat. J. Oilseeds Res. 22 (1): 238-239. 